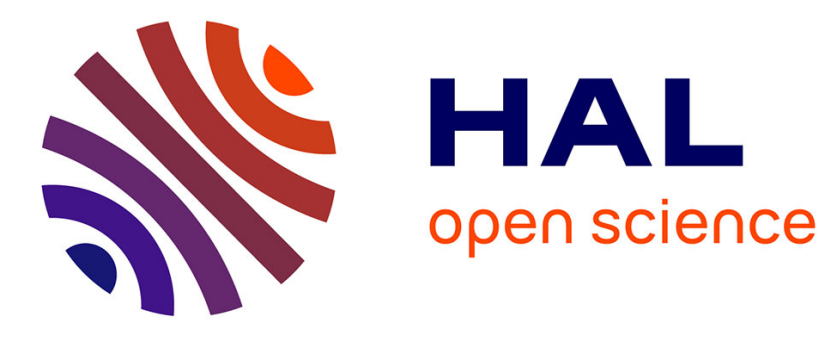

\title{
Determining the effective hydraulic properties of a highly heterogeneous soil horizon
}

Anatja Samouëlian, Isabelle I. Cousin, Cécile Dagès, Anthony Frison, Guy Richard

\section{- To cite this version:}

Anatja Samouëlian, Isabelle I. Cousin, Cécile Dagès, Anthony Frison, Guy Richard. Determining the effective hydraulic properties of a highly heterogeneous soil horizon. Vadose Zone Journal, 2011, 10 (1), pp.450-458. 10.2136/vzj2010.0008 . hal-02645588

\section{HAL Id: hal-02645588 \\ https://hal.inrae.fr/hal-02645588}

Submitted on 29 May 2020

HAL is a multi-disciplinary open access archive for the deposit and dissemination of scientific research documents, whether they are published or not. The documents may come from teaching and research institutions in France or abroad, or from public or private research centers.
L'archive ouverte pluridisciplinaire HAL, est destinée au dépôt et à la diffusion de documents scientifiques de niveau recherche, publiés ou non, émanant des établissements d'enseignement et de recherche français ou étrangers, des laboratoires publics ou privés. 


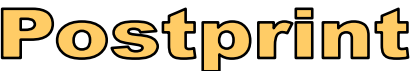

Version définitive du manuscrit publié dans / Final version of the manuscript published in :

Vadose Zone Journal, 2011, 10(1), 450-458, $\quad$ http://dx.doi.org/10.2136/vzj2010.0008

1 Determining the effective properties of a highly heterogeneous horizon: Estimations by

2 numerical simulations and calculations by analytical equations

3

4 Samouëlian A. ${ }^{1, *}$, Cousin I. ${ }^{1}$, Dagès C. ${ }^{2}$, Frison A. ${ }^{1}$, Richard G. ${ }^{1}$

5

$6 \quad{ }^{1}$ INRA, UR 0272 - Unité de Science du Sol, Centre de recherche d'Orléans, 2163 Avenue de

7 la Pomme de Pin, CS 40001 Ardon, 45075 Orléans Cedex 2, France

$8 \quad$ INRA, UMR LISAH - Bat 24, 2 place Viala, 34060 Montpellier Cedex, France

9

$10 *$ Corresponding author:

11 Phone: +33238417849

12 Fax: + 33238417869

13 E-mail: Anatja.Samouelian@ orleans.inra.fr

15 Keywords:

16 Upscaling techniques, heterogeneous soil horizon, effective hydraulic properties 


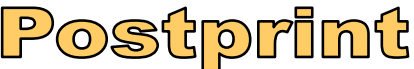

Version définitive du manuscrit publié dans / Final version of the manuscript published in :

Vadose Zone Journal, 2011, 10(1), 450-458, ～http://dx.doi.org/10.2136/vzj2010.0008

\section{Abstract}

In this study, we have attempted to determine the effective hydraulic properties of a highly heterogeneous soil horizon composed of two elementary pedological volumes (EPVs). Our upscaling approach was guided by the scaleway approach introduced by Vogel and Roth (2003), in which the properties of a complex system can be estimated by multiple discrete upscaling steps. This approach was tested on a dataset from laboratory measurements of hydraulic conductivity at EPV scale, while explicit 3D soil structure was considered at horizon scale. We then formulated a decision tree to guide the user to choose the appropriate upscaling method to determine effective hydraulic conductivity at horizon scale. In the case of low contrast between hydraulic conductivities at EPV scale, the effective hydraulic conductivity at horizon scale can be achieved by calculating the Wiener bounds, which requires only the proportion of the different EPVs. In the case of high contrast between hydraulic conductivities at EPVs scale, we recommend either calculating the Cardwell and Parson bounds, or performing a direct 3D numerical simulation to solve Richard's equation, which requires an explicit representation of the 3D structure of the soil horizon. The Cardwell and Parsons bounds remain a good and easily available approximation. Otherwise, more accurate estimation can be obtained by numerical simulation though this is time-consuming. A decision map is proposed to help choosing the best method for estimating effective hydraulic conductivity. 


\section{Introduction}

Hydraulic properties are often key parameters in environmental simulations and it is usually necessary to obtain them at horizon scale. In this context, soil horizons represent the reference soil volume in terms of soil functioning. Nevertheless, in many cases soil horizons are heterogeneous, for example, in stony horizons (Cousin et al., 2003), cultivated horizons (Richard et al., 2001), and also specific weathering horizons like those in Albeluvisols (Diab et al., 1988; Frison et al., 2009). In these cases, the determination of hydraulic properties remains difficult. Consequently, two possibilities are offered. The soil horizon can be described either by an explicit structure with distinctive hydraulic properties, or by effective soil hydraulic parameters. The first possibility requires $2 \mathrm{D}$ or, even better, 3D modeling, though the latter is not always practical to carry out. The second possibility is based on the assumption that the soil horizon can be represented by a homogeneous structure if it is possible to take into account the hydraulic properties at a lower scale. Nevertheless, the determination of effective hydraulic properties in heterogeneous horizons cannot be done by classical laboratory experiments on decimetric samples, such as the Multi-Step-Outflow (van Dam et al., 1994) or the Wind evaporation experiment (Wind, 1968). According to the WRB (1998), these heterogeneous horizons can be described as a combination of different elementary soil pedological volumes that have different chemical and mineralogical compositions and physical properties. For example, in the case of an Albeluvisol we can distinguish ochre and pale volumes resulting from soil evolution; in the case of a cultivated horizon, compacted and uncompacted soil clods result from mechanical stress. Here, we propose to determine the effective properties at the horizon scale based on the scaleway upscaling approach introduced by Vogel and Roth (2003). In this upscaling approach, spatial variability is considered to exist at multiple scales, and the system can be divided into multiple discrete upscaling steps. Indeed, this approach permits dealing with multiscale 
heterogeneities without making assumptions about the heterogeneities of the underlying structure, because the latter is taken into account explicitly.

The aim of this paper is threefold: i) to determine the hydraulic properties at the scale of the soil's elementary volume, ii) to discuss benefits and disadvantages of the different analytical methods for upscaling, and iii) to compare these methods with the estimation of the effective

First, the determination of the hydraulic properties at the elementary scale of soil pedological volumes is done by adapting the method proposed by Meadows et al. (2005). The second step consists in developing different strategies to determine the effective hydraulic properties at horizon scale. Renard and de Marsily (1997) discussed of different analytical methods based on the simple calculation of bounds to estimate the effective hydraulic conductivity in heterogeneous porous media. Until now, these methods have mostly been used in petroleum

Version définitive du manuscrit publié dans / Final version of the manuscript published in :

Vadose Zone Journal, 2011, 10(1), 450-458, $\quad$ http://dx.doi.org/10.2136/vzj2010.0008

$$
\text { hydraulic conductivity by using a direct 3D numerical simulation. }
$$

engineering and in hydrogeology. Moreover, recent research to determine the effective hydraulic properties of soil has often neglected natural soils and opted for simulated structures (Knudby et al., 2006; Samouëlian et al., 2007; Durner et al., 2008). Here, we propose to apply the analytical methods put forward by Renard and de Marsily (1997) in the context of Soil Science, to natural soil heterogeneities and real data measurements of hydraulic properties at local scale. To achieve this, we use an explicit representation of 3D soil structure measured by electrical resistivity tomography (Frison 2008). We also test the accuracy of analytical characteristics which can be easily computed once the structure of hydraulic properties is known. 


\section{Material and Methods}

\subsection{Soil characteristics and structure}

The soil studied was an Albeluvisol that exhibited several horizons composed by the juxtaposition of two Elementary Pedological Volumes (EPVs). Here, we have focused on the E\&BT horizon, from 30 to $55 \mathrm{~cm}$ depth. The EPVs in this horizon can be visually distinguished by their colours (ochre and pale). Their chemical and mineralogical compositions (Montagne et al., 2008) and their different modes of hydraulic functioning (Frison et al., 2009) were analysed on clods of the two types of EPVs, each clod being large enough to be a Representative Elementary Volume of the EPV. This is consistent with previous studies on E\&Bt horizons (Diab et al., 1988; Wopereis et al., 1993). The pale EPVs contained more silt whereas the ochre EPVs contained more clay (Table 1), but the proportion of clay increased with depth inside the whole sample volume whatever the EPV. The bulk density of the EPVs was around $1.5 \mathrm{~g} . \mathrm{cm}^{-3}$ and was not significantly different between the two types of EPV (Table 2). Further works conducted by Frison (2008) provided the 3D structure of the soil horizon, and the proportion of each EPV. The characterisation of this E\&Bt horizon was done during autumn 2006, when no macropore was observed in the field. As a consequence, only two types of EPVs, ochre EPV and pale EPV, represent the structure of the horizon. The 3D structure of this heterogeneous horizon was obtained by electrical resistivity measurements (fig. 1). A 3D soil block (90 cm x $52 \mathrm{~cm}$ x $30 \mathrm{~cm})$ with the explicit localisation of the ochre and pale EPVs was obtained after a simple binary threshold of the electrical resistivity data. The threshold was chosen by comparison between the binary resistivity image of the top of the horizon and its picture from photography (Frison, 2008). Moreover, the proportion of each EPV type was calculated on this soil block: $57 \%$ for the ochre EPVs and $43 \%$ for the pale EPVs respectively. 
Version définitive du manuscrit publié dans / Final version of the manuscript published in :

Vadose Zone Journal, 2011, 10(1), 450-458,

\subsection{Determining hydraulic properties at EPV scale}

To calculate the effective hydraulic properties at horizon scale, experiments were first conducted at EPV scale. Large undisturbed blocks of the E\&BT horizon - about 10,000 $\mathrm{cm}^{3}$ were sampled when the soil was near field capacity during the autumn season. They were carefully stored at $4^{\circ} \mathrm{C}$ to avoid both structural disturbance by biological activity and loss of water. Before the experiments, each soil block was gently cut by hand, to separate the ochre EPVs and the pale EPVs, without destroying their structure. Each EPV was roughly cylindrical, with a diameter of at least $2 \mathrm{~cm}$ and a height of about $4 \mathrm{~cm}$.

To keep the soil sample intact and avoid destruction during the experiments, the EPVs were embedded in paraffin wax and then placed in small plastic cylinders $(6 \mathrm{~cm}$ in diameter, $6 \mathrm{~cm}$ in height).

Saturated hydraulic conductivity was determined with the constant-head method (Stolte, 1992) by using a mini-permeameter whose diameter was equal to the diameter of the plastic cylinder. After this experiment, the method proposed by Meadows et al. (2005) was adapted. The cylinder was placed on a mass balance and a mini tensiometer was inserted horizontally at the centre of the saturated EPV and equipped with a pressure transducer to continuously measure soil water potential. From these experimental data, the water retention curve and the unsaturated hydraulic conductivity were estimated by inverse modelling using HYDRUS-1D (Simunek et al., 2005). The water retention curve was parameterized by the modified van Genuchten equation with an air-entry value equal to $-2 \mathrm{~cm}$, and the unsaturated hydraulic conductivity was parameterized by the Mualem-van Genuchten equation (Mualem, 1976; van Genuchten, 1980):

$$
\begin{cases}\theta=\theta_{\text {sat }} & \text { if } h \geq-2 \mathrm{~cm} \\ \frac{\theta-\theta_{r}}{\theta_{s}-\theta_{r}}=\left[1+(\alpha|h|)^{n}\right]^{-(1-1 / n)} & \text { if } h<-2 \mathrm{~cm}\end{cases}
$$




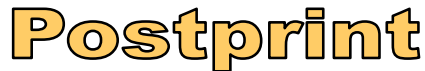

Version définitive du manuscrit publié dans / Final version of the manuscript published in :

Vadose Zone Journal, 2011, 10(1), 450-458， http://dx.doi.org/10.2136/vzj2010.0008

$$
\begin{aligned}
& \begin{cases}K(S e)=K_{0} & \text { if } h \geq-2 \mathrm{~cm} \\
K(S e)=K_{0} S e^{l}\left[1-\left(1-S e^{1 / m}\right)^{m}\right]^{2} & \text { if } h<-2 \mathrm{~cm}\end{cases} \\
& \text { with } S e=\frac{\theta-\theta_{r}}{\theta_{s}-\theta_{r}}
\end{aligned}
$$

135 where $h$ is the water potential $(\mathrm{m}), \theta$ the volumetric water content $\left(\mathrm{m}^{3} \mathrm{~m}^{-3}\right), \theta_{s}$ the saturated water content $\left(\mathrm{m}^{3} \mathrm{~m}^{-3}\right), \theta_{\mathrm{r}}$ the residual water content $\left(\mathrm{m}^{3} \mathrm{~m}^{-3}\right), l$ the tortuosity factor, here taken as equal to $0.5, K_{0}\left(\mathrm{~m} . \mathrm{s}^{-1}\right)$ the hydraulic conductivity at $h=0, m$, and $n$ and $\alpha\left(\mathrm{m}^{-1}\right)$ are fitting parameters.

We chose the following conditions for the inversion:

Boundary conditions: no flux occurred at the lower EPV boundary while the flux at the surface of the EPV was recorded during the experiment and corresponded to the loss of mass of the whole sample, i.e. the loss of water through evaporation.

Initial condition: a linear distribution of water potential with depth was used.

144 The objective function of the inverse problem was defined with both the values of the water 145 potential recorded in the middle of the sample by the microtensiometer, and the values of the water content calculated from the loss of mass recorded by the mass balance. Among the parameters to be determined, two of them were fixed before the inversion: parameter $K_{0}$ was taken as equal to the measured value $\left(K_{0}=K_{\text {sat }}\right)$ with $K_{\text {sat }}$ being the saturated hydraulic conductivity; parameter $\theta_{s}$ was taken as being equal to the porosity and estimated with the EPV mass and the EPV volume, assuming a particle density equal to $2.65 \mathrm{~g} \mathrm{~cm}^{-3}$. Quality of the fit was check through the mass balance error.

\subsection{Determination of effective hydraulic properties}

\subsubsection{Case studies}


156 Three case studies were analysed from the results at EPV scale: case 1: the highest contrast 157 between the hydraulic properties of the ochre and pale EPVs was taken into account; case 2: 158 the mean value of the hydraulic properties calculated for each type of EPV was taken into account; and case 3: the lowest contrast of hydraulic properties between the ochre and the pale 160 EPVs was taken into account.

\subsubsection{Effective water retention curve}

163 The effective water retention curve was obtained from the additive properties of the water retention curves at local scale, introduced by Durner (1994). This was achieved by an expansion of the modified van Genuchten parametrization to a k-modal form (Vogel et al., 2008):

$$
S_{e}(h)=\sum_{i=1}^{k} \omega_{i}\left[\left(1+\alpha_{i} h\right)^{n_{i}}\right]^{-1+1 / n_{i}}
$$

168 where $S_{e}(h)$ is the effective water saturation. The relative weight of the different modes $\omega_{i}$ fulfilled the condition $\sum_{i} \omega_{i}=1$ while $n_{i}$ and $\alpha_{i}$ are the related van Genuchten parameters (van Genuchten, 1980). In our study, $\omega$, the volume proportion of the different EPVs was equal to 0.43 for the pale EPVs and to 0.57 for the ochre EPVs.

\subsubsection{Effective hydraulic conductivity}

The effective hydraulic conductivity was determined with two different methods: numerical 3D variably saturated flow modeling, and an analytical method with the calculation of mathematical bounds. It should be noted that the analytical method consisted in fast and easy calculation, compared to the numerical one that requires a numerical $3 \mathrm{D}$ code to solve 178 Richards equation. 
Version définitive du manuscrit publié dans / Final version of the manuscript published in : Vadose Zone Journal, 2011, 10(1), 450-458, ～http://dx.doi.org/10.2136/vzj2010.0008

181 The effective hydraulic conductivity $K_{\text {eff }}(h)$ of the E\&Bt horizon was obtained by solving 182 Richards equation using Hydrus 3D (Simunek et al., 07). The 3D soil structure at horizon 183 scale (fig. 1) was used to allocate each node (15 600 in total) of the finite element mesh to 184 ochre or pale soil hydraulic properties. We used a modified hexahedral mesh with 80850 185 elements to spatially describe the soil horizon. The average size of each element was about 2 $186 \mathrm{~cm}^{3}$, whereas the sizes of the pale and ochre EPVs ranged from some centimeters to 187 decimeters.

188 Numerical simulations were the same as described by Samouëlian et al. (2007). A steady-state 189 flow regime was simulated by applying a constant water potential $h$ at the upper and the lower 190 boundary, so that gravity was the only driving force and the soil potential was approximately 191 constant throughout the domain. The initial condition was a constant pressure head, whereas 192 the vertical boundaries were considered as no-flux boundaries since the flow was assumed to 193 be mainly vertical. This calculation was done for 102 pressures starting from saturated $(h=$ $194 \mathrm{OhPa})$ to unsaturated conditions $(h=-10000 \mathrm{hPa})$. For each water potential value, the 195 simulation time was chosen so that the steady-state flow condition was reached. The highest 196 mass balance error that was accepted was $0.003 \%$. Finally, we obtained $K_{\text {eff }}(h)$ which is 197 equal to the simulated flux.

\subsubsection{Calculation of the analytical bounds}

200 Three types of analytical bounds, namely those of Wiener (1912), Matheron (1967), Cardwell 201 and Parsons (1945), were calculated to estimate the hydraulic conductivity of the 202 heterogeneous E\&Bt soil horizon.

203 The calculation of the Wiener and Matheron bounds is based on an assumption of the spatial arrangement of the different EPVs constituting the soil horizon and takes into account their 
proportion. The Wiener bounds assumed a layered model structure. When the flux is parallel

206 to the main direction of organization of the two types of EPVs, the effective conductivity at

$$
m_{a}(h)=\sum_{i=1}^{2} \omega_{i} K_{i}(h)
$$

210 where $\omega_{i}$ represents the volume proportion of each EPV and $K_{i}(h)$ represents the hydraulic

211 conductivity of EPV i at water potential $h$.

212 When the flux is perpendicular to the main direction of organization of the two types of EPVs, the effective conductivity at each water potential, $m_{h}(h)$, is given by the harmonic 214 mean of the hydraulic conductivity of each EPV:

$$
1 / m_{h}(h)=\sum_{i=1}^{2} \omega_{i} / K_{i}(h)
$$

216 In a more complex arrangement of the different types of EPV, the effective hydraulic 217 conductivity of the E\&BT horizon $K_{\text {eff }}(h)$ is comprised between these two theoretical bounds:

$$
m_{h}(h) \leq K_{\text {eff }}(h) \leq m_{a}(h)
$$

219 In the calculation of the Matheron bound, we consider that the geometry of the porous

220 medium is isotropic. In this case the effective hydraulic conductivity $K_{\text {eff }}(h)$ is equal to:

$$
K_{\text {eff }}(h)=m_{a}(h)^{\alpha} m_{h}(h)^{1-\alpha} \quad \text { with } \alpha=(D-1) / D
$$

222 where $\mathrm{D}$ is the spatial dimension.

223 Cardwell and Parsons (1945) proposed to take account of the spatial 3D arrangement of the 224 soil horizon to define the upper and lower bounds. The effective conductivity in a given 225 direction is bounded by: 1) the arithmetic mean of the harmonic means calculated on each cell 226 line parallel to the main flow direction (lower bound); 2) the harmonic mean of the arithmetic means on each slice of a cell perpendicular to the main flow direction (upper bound). If the 


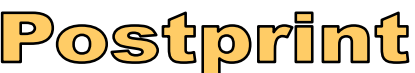

Version définitive du manuscrit publié dans / Final version of the manuscript published in :

Vadose Zone Journal, 2011, 10(1), 450-458, http://dx.doi.org/10.2136/vzj2010.0008

228 main flow is orientated along the vertical $\mathrm{z}$ axis, the effective conductivity $K_{\text {eff }}(h)$ is then

229 bounded by:

$$
m_{a}^{x}(h)\left[m_{a}^{y}(h)\left(m_{h}^{z}(h)\right)\right] \leq K_{e f f}(h) \leq m_{h}^{z}(h)\left[m_{a}^{y}(h)\left(m_{a}^{x}(h)\right)\right]
$$




\section{3. Results}

\section{3.1. Water retention curves of each pair of EPVs and the effective water retention curve at}

\section{3 horizon scale}

\section{3.1.1 Comparison of the water retention curve for the pale and ochre EPVs}

235 Figure $2 \mathrm{a}$ presents the water retention curve estimated from evaporation experiments for 17 236 pale and ochre EPVs. For potentials higher than about $-1000 \mathrm{hPa}$, the volumetric water 237 content was generally higher in the pale EPVs than in the ochre ones, which was in agreement with higher porosity due to biological structures (earthworm and plant roots) observed in the field in the pale EPVs. On the contrary, for water potentials lower than $-1000 \mathrm{hPa}$, the water content was higher in the ochre EPVs, due to their higher clay content (Table 1) (Montagne et al., 2008; Frison et al., 2009). Nevertheless, the variability in the water retention curve within the different EPVs was high. Statistical tests on water content for water potentials equal to -10 $\mathrm{hPa},-33 \mathrm{hPa},-100 \mathrm{hPa},-330 \mathrm{hPa},-500 \mathrm{hPa}$ and $-1000 \mathrm{hPa}$ showed that the difference in water content between the two types of EPV was significant for water potentials equal to or higher than $-100 \mathrm{hPa}$ and non significant for water potentials equal to or lower than $-330 \mathrm{hPa}$. 246 The hydraulic parameters of the three cases are summarized in Table 3.

\subsubsection{Calculation of the effective water retention curve at horizon scale}

249 According to equation [4], the effective water retention curve at the horizon scale must be 250 localized inside the domain defined by the water retention curves of the pale and ochre EPVs. 251 Because the proportion of ochre EPVs was slightly higher (57\%) compared to the pale EPVs $252(43 \%)$, the resulting effective water retention curve was closer to the ochre EPV water retention curve. Figure $2 \mathrm{~b}$ presents the results for case 1 ; nevertheless the tendency was the same for the other cases 1 and 2, but the amplitude of the contrast between the water retention curves at EPV scale became decreasingly significant (results not shown here). 
Version définitive du manuscrit publié dans / Final version of the manuscript published in : Vadose Zone Journal, 2011, 10(1), 450-458,

\subsection{Hydraulic conductivity of each pair of EPVs and determination of effective hydraulic}

conductivity

\subsubsection{Comparison of the hydraulic conductivity curve for the pale and ochre EPVs}

Figure 3 a presents the hydraulic conductivity curve for 8 pale and 9 ochre EPVs. Statistical tests performed on the logarithmic value of hydraulic conductivity for water potentials equal to those already studied for the water retention curve, i.e. $-10 \mathrm{hPa},-33 \mathrm{hPa},-100 \mathrm{hPa},-330$ $\mathrm{hPa},-500 \mathrm{hPa}$ and $-1000 \mathrm{hPa}$, showed that hydraulic conductivity was always significantly different for the pale EPVs and for the ochre EPVs: hydraulic conductivity was higher in the pale EPVs whatever the water potential.

As shown in figure $3 \mathrm{~b}$, the contrast in hydraulic conductivity between ochre and pale EPVs was different for the three cases. The difference in hydraulic conductivity between pale and ochre EPVs was maximal for a water potential around $-1000 \mathrm{hPa}$ for case 1 , and around -400 hPa for case 2. For more negative water potentials, the difference decreased slightly. Concerning case 3 , the difference in hydraulic conductivity between the ochre and pale EPVs was negligible. To check this difference, we also calculated the surface area, defined by integral differences, between the two hydraulic conductivity curves for each case (fig. 4). As seen in Table 4, this surface area varied by one order of magnitude between case 1 and case 3 .

\subsubsection{Calculation of the effective hydraulic conductivity curve at horizon scale}

The estimation of the effective hydraulic conductivity curve by the numerical simulation was assumed to be the closest to the real hydraulic conductivity and was thus considered as the reference hydraulic conductivity curve. As expected, whatever the case, it was between the hydraulic conductivity curves of each EPV, and was closer to the hydraulic conductivity of the pale EPVs (fig. 4), although the proportion of ochre EPVs was higher. This example backs up the argument that hydraulic conductivity is above all correlated to the soil structure. 
Version définitive du manuscrit publié dans / Final version of the manuscript published in : Vadose Zone Journal, 2011, 10(1), 450-458,

For case 3 (fig. 4c), the effective hydraulic conductivity curves estimated by the numerical simulation and calculated by the analytical bounds merged as the contrast in hydraulic conductivity was low. Contrary to case 3 , cases 1 and 2 presented distinct effective hydraulic conductivity curves. As seen in figure $4 \mathrm{a}$ and $4 \mathrm{~b}$, the Wiener bounds and the Cardwell \& Parsons bounds delineated a surface area inside the domain of the hydraulic conductivity curves of the ochre and pale EPVs. These domains included the effective hydraulic conductivity curve estimated by the numerical simulation. By definition the Cardwell \& Parsons domain is included inside the Wiener domain. Indeed the heterogeneous structure is taken into account by the Cardwell \& Parsons bounds. The Wiener bounds assume an extreme geometric structure of soil with a layered structure. This is in agreement with calculation of the surface areas of the two domains: $S_{\text {Wiener }} \geq S_{\text {Cardwell-Parsons, whatever the case (Table 4). }}$

The results of our study showed that the high Wiener bound (calculation of the arithmetic mean) was closer to the numerical simulation than the low Wiener bound (calculation of the harmonic mean). This means that the general structure of the E\&BT horizon was more or less parallel to the water flow. This was consistent with field observations of vertical tongues of pale EPVs and image analysis observations (Cornu et al., 2007).

\section{Discussion}

As shown previously, for the estimation of the effective hydraulic conductivity at horizon scale, different situations could occur, depending on the contrast of the hydraulic conductivity of each elementary EPV. Here, we propose a decision tree to guide the user in choosing the method best-adapted for estimating the effective hydraulic conductivity of a heterogeneous soil horizon (fig. 5). First of all, for any anisotropic medium like soil, the structure must be studied roughly, for example, by qualitative soil profile observation. The two extreme cases consist in a layered porous medium, where the elementary pedological volumes would be 
Version définitive du manuscrit publié dans / Final version of the manuscript published in : Vadose Zone Journal, 2011, 10(1), 450-458， ～http://dx.doi.org/10.2136/vzj2010.0008

either parallel or perpendicular to the water flow. Between these two extreme structures, various possibilities of structure topology and connectivity can be considered, as is often the case for the natural soil horizon. Indeed, recent research has pointed out that the topology of the sub-scale structure may be of crucial importance for upscaling hydraulic conductivity (Western et al., 2001; Zinn and Harvey, 2003; Knudby et al., 2006; Samouëlian et al., 2007). Here, we propose to take into account not only the topology but also the contrast between the hydraulic conductivity curves at EPV scale to choose the appropriate upscaling method: either estimation by numerical simulation or calculation using the analytical bounds.

i) When the contrast between the hydraulic conductivity curves of the two types of EPV is low, the effective hydraulic conductivity can be rapidly and easily estimated by the calculation of the domain defined by the Wiener bounds. This method requires only the volume proportion of the different EPVs.

ii) When the contrast between the hydraulic conductivity curves of the two types of EPV is high, we recommend either estimating the effective hydraulic conductivity by numerical simulation, or calculating it with Cardwell-Parsons bounds. Both methods require the 3D structure of the soil horizon. An initial estimation could be given quickly by the calculation of the Cardwell and Parsons bounds. Depending on the required accuracy, this first estimation can be sufficient. Otherwise, a more accurate estimation can be provided by numerical simulation. Nevertheless, it should be noted that this numerical simulation is much more time consuming than the calculation of analytical bounds.

Nevertheless, determining an absolute value for a "high" or a "low" contrast of hydraulic conductivity at EPV scale remains difficult. One way of deciding whether Wiener bounds can be used consists in calculating their ratio, which itself depends on the ratio between the 
EPV. This ratio $R_{W}$ is equal to:

$$
R_{W}=\frac{\left[\omega_{p} \frac{K_{p}(h)}{K_{o}(h)}+\left(1-\omega_{p}\right)\right]\left[\omega_{p}+\left(1-\omega_{p}\right) \frac{K_{p}(h)}{K_{o}(h)}\right]}{\frac{K_{p}(h)}{K_{o}(h)}}
$$

where $K_{p}(h)$ and $\left(K_{o}(h)\right)$ represents the hydraulic conductivity of the pale EPVs the ochre EPVs respectively, while $\omega_{\mathrm{p}}$ is the volume fraction of the pale EPV. When the contrast between the hydraulic conductivity curves is low, the $R_{W}$ ratio between the two Wiener bounds is close to one. This means that the Wiener bounds enclose a rather narrow region in which the actual effective hydraulic conductivity is located. For more complex cases, we propose a decision map based on the $R_{W}$ ratio, in order to simultaneously track the effect due to the contrast between hydraulic conductivity at EPV scale, and that for each possible proportion between the two EPVs. The hydraulic conductivity contrast was extended up to 4.5 in log scale, covering by this way the range of hydraulic properties proposed by Vogel et al., (2006) between macropores and a soil horizon. In our study, we consider that the Wiener bounds could be correctly applied when the $R_{w}$ value is lower than 3 (fig. 6). Nevertheless the $R_{w}$ threshold value has to be considered case to case by the user, depending i) on the accuracy of the measurements themselves at the lower scale, and ii) on the expected accuracy required for the simulation. In our survey, the cases 1 and 2 have $R_{w}$ ratios lower than 3 and the use of Wiener bounds remained then acceptable. Consequently, by calculating effective hydraulic conductivity it is possible to avoid the difficulties related to numerical simulation. For case 3, the $R_{W}$ ratios were from around 3 to 100 ; the contrast between the hydraulic conductivity curves of the pale and ochre EPVs therefore remained too high (around 2.5 in log scale) to estimate the effective hydraulic conductivity by using the Wiener domain. In this case, the 
calculation of the effective hydraulic conductivity curve by the Cardwell and Parsons bounds remained the best and most easily available approximation.

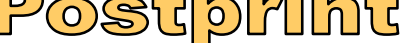

Version définitive du manuscrit publié dans / Final version of the manuscript published in :

Vadose Zone Journal, 2011, 10(1), 450-458, $\quad$ http://dx.doi.org/10.2136/vzj2010.0008

This decision tree was built with the assumption that the structure was bimodal at horizon scale. Nevertheless, according to the scaleway upscaling approach introduced by Vogel and Roth (2003), the applied concept could be generalized to estimate effective hydraulic conductivity at scale $\mathrm{n}$ from knowledge of scale $\mathrm{n}-1$. With respect to Wiener bounds assuming a layered structure this suggest a simple way for upscaling to the scale of soil profiles or even watershed. Nevertheless, this approach only allows the calculation of the vertical flux component, so that this concept would be valid only when lateral flows are negligible or else can be neglected.

At profile scale, the general structure of the soil is layered, with horizons sub-parallel to the soil surface and generally perpendicular to the main water flow. Consequently, an easy way to estimate the effective hydraulic properties at profile scale would be to calculate the low Wiener bound, that is to say the harmonic mean of the hydraulic conductivity of the different superimposed soil horizons weighted by their thickness (fig. 5).

At small watershed scale, it can be assumed that the general organization of the pedological mantel consists of a juxtaposition of soil units. If we hypothesize that the general hydrodynamic functioning of this watershed is vertical, and that the hydraulic conductivity curve of each soil unit is known, we can calculate the effective hydraulic conductivity curve of the watershed from the high Wiener bound, that is to say the arithmetic mean weighted by the surface area of each soil unit. 
Version définitive du manuscrit publié dans / Final version of the manuscript published in : Vadose Zone Journal, 2011, 10(1), 450-458,

\section{Conclusion}

In this study we investigated the impact of using different analytical bounds to upscale the effective hydraulic properties of a complex horizon, and especially hydraulic conductivity. The calculations of the analytical bounds were either based on the volume proportion of the different EPVs (Wiener and Matheron), or on the 3D structure (Cardwell and Parson), which included additional topological and connectivity information about soil structure. As already acknowledged in the literature, prior knowledge of topology and connectivity leads to more precise determination of effective hydraulic conductivity. However, because calculating analytical bounds is much easier than performing a numerical simulation based on a 3D structure, we defined the case in which the first method would lead to satisfactory results. We demonstrated that the contrast of hydraulic conductivity between the two EPVs was crucially important for choosing the most appropriate method to estimate effective hydraulic conductivity. Indeed, for a low contrast between these two EPVs, it was shown that the Wiener method, which requires only the volume proportions of each EPV, provided satisfactory results. For high contrast between the two EPVs, an adequate upscaling method required the 3D soil structure, i.e. topology and connectivity. For a hydraulic contrast equal or higher than the case 3 , the use of Wiener bounds is then inadvisable. The calculation using Cardwell and Parson bounds is recommended at first because it is simpler to compute. If the accuracy of the calculated effective hydraulic conductivity is not sufficient, the numerical simulation is then the most relevant method.

We then used our results to propose a decision map that can be used for other studies to help choosing the appropriate analytical bounds as a function of the accuracy expected up to a conductivity contrast of 4.5 in log scale.

Our results are based on a natural soil horizon defined by only two EPVs, but extrapolation to more than two EPVs is easy. The sole restriction is the need to define the hydraulic properties 


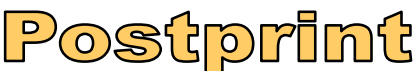

Version définitive du manuscrit publié dans / Final version of the manuscript published in :

Vadose Zone Journal, 2011, 10(1), 450-458, $\quad$ http://dx.doi.org/10.2136/vzj2010.0008

at EPV scale. Moreover this approach was tested on real measurements at EPVs scale combined with an explicit 3D structure at horizon scale, but it can be generalized for estimating effective hydraulic conductivity at other scales. For example, this approach could be applied to define effective soil hydraulic properties for each soil unit at watershed scale, leading to better account being taken of heterogeneous soil horizons in simulations of environmental functioning.

406 Acknowledgements: Hervé Gaillard, Guillaume Giot and Pierre Courtemanche are gratefully 407 acknowledged for their help during field sampling and laboratory experiments. 


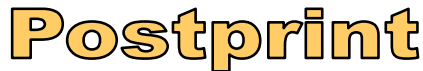

Version définitive du manuscrit publié dans / Final version of the manuscript published in :

Vadose Zone Journal, 2011, 10(1), 450-458, ․ㅡㄹ.//dx.doi.org/10.2136/vzj2010.0008

\section{References}

410 Cardwell, W.T. and Parsons, R.L. 1945. Average permeabilities of heterogeneous oil sands. Trans. Am. Inst. Mining. Met. Pet. Eng: 34-43.

Cornu, S. Montagne, D., Maguin, F., Le lay, C., Chevallier, P. and Cousin, I. 2007. Influence of human impacts on Albeluvisol analysed by X-ray microfluorescence: Relative evolution of the transforming front at the tongue scale. Science of the Total Environment, 377(2-3): 244-254.

Cousin, I., Nicoullaud, B. and Coutadeur, C. 2003. Influence of rock fragments on the water retention and water percolation in a calcareous soil. Catena, 53(2): 97-114.

Diab, M., Merot, P. and Curmi, P. 1988. Water-Movement in a Glossaqualf as measured by two tracers. Geoderma, 43(2-3): 143-161.

Durner, W. 1994. Hydraulic conductivity estimation for soils with heterogeneous pore structure. Water Resources Research, 30(2): 211-223.

Durner, W., Jansen, U. and Iden, C. 2008. Effective hydraulic properties of layered soils at the lysimeter scale determined by inverse modeling. European Journal of Soil Science, 59, 114-124.

Frison, A., Cousin, I., Montagne, D. and Cornu, S. 2009. Soil hydraulic properties in relation to local rapid soil changes induced by field drainage: a case study. European Journal of Soil Science, 60(4): 662-670.

Frison, A. 2008 Analyse et modélisation des propriétes hydriques d'un horizon hétérogène de sol. Thèse de l'Université d'Orléans, 228 p.

Knudby, C., Carrera, J., Bumgardner, J.D. and Fogg, G.E. 2006. Binary upscaling - the role of connectivity and a new formula. Advances in Water Resources, 29: 590-604.

Matheron, G., 1967. Eléments pour une théorie des milieux poreux, Paris.

Meadows, D., Young, M.H. and McDonnald, E. 2005. A laboratory method for determing the unsaturated hydraulic properties of soil peds. Soil Science Society of America Journal, 69: 807815.

Montagne, D. Cornu, S., Josiére, O., Le Forestier, L., Daroussin, J. and Cousin, I. 2008. Soil drainage as a factor of human-induced soil evolution: quantification of such an evolution in an Albéluvisol. Geoderma, 145(3-4): 426-438. 
437 Mualem, Y. 1976. A new model for predicting the hydraulic conductivity of unsaturated porous media. Water Resources Research, 12: 513-519

439 Renard, Ph. and de Marsily, G. 1997. Calculating equivalent permeability: A review. Advances in Water Resources, 20(5-6): 253-278.

441 Richard, G., Cousin, I., Sillon, J.F., Bruand, A. and Guerif, J. 2001. Effect of compaction on the porosity of a silty soil: influence on unsaturated hydraulic properties. European Journal of Soil Science, 52(1): 49-58.

Samouëlian, A., Vogel, H.J. and Ippisch O. 2007. Upscaling hydraulic conductivity on the topology of the sub-scale structure. Advances in Water Resources, 30, 1179-1189.

446 Šimůnek J., Sejna M. and van Genuchten M.Th., 2007. Software package for simulating the two and three dimensional movement of water, heat and multiple solutes in variably saturated media, user manual, version 1.07203 p.

Šimůnek, J., van Genuchten, M. Th. and Šejna, M. 2005. The HYDRUS-1D Software Package for Simulating the Movement of Water, Heat, and Multiple Solutes in Variably Saturated Media, Version 3.0, HYDRUS Software Series 1, Department of Environmental Sciences, University of California Riverside, Riverside, California, USA, 270 pp.

Stolte, J. 1992. Determination of the saturated hydraulic conductivity using the constant head method. Manual soil physical measurements, version 2.0. Technical Document sc-dlo, Wageningen, 4p.

van Genuchten, M.T. 1980. A Closed-Form Equation For Predicting The Hydraulic Conductivity of Unsaturated Soils. Soil Science Society of America Journal, 44(5): 892-898.

Vogel, H.J., Samouëlian, A. and Ippisch, O. 2008. Multi-step and two-step experiments in heterogeneous porous media to evaluate the relevance of dynamic effects. Advances in Water Resources, 31:181-188.

Vogel H.J., Cousin I., Ippisch O., Bastian P., 2006. The dominant role of structure for solute transport in soil: experimental evidence and modelling of structure and transport in a field experiment.

Vogel, H.J. and Roth, K. 2003. Moving through scales of flow and transport in soil. Journal of Hydrology, 272(1-4): 95-106. 


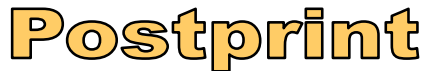

Version définitive du manuscrit publié dans / Final version of the manuscript published in :

Vadose Zone Journal, 2011, 10(1), 450-458, http://dx.doi.org/10.2136/vzj2010.0008

Western, A.W., Blöschl, G. and Grayson, R.B. 2001. Toward capturing hydrologically significant connectivity in spatial patterns. Water Resources Research, 37(1): 83-97.

Wiener, O. 1912. Abhandlungen der Mathematisch. Physischen Klasse der königlichen sächsischen Gesellschaft(32): 309 .

Wind, G.P. 1968. Capillary conductivity data estimated by a simple method. In: E. P.E. Rijtema and H. Wassink (Editor), Water in the Unsaturated Zone, Gentbrugge, Belgium, pp. 181-191.

Wopereis, M.C.S., Kropff, M.J., Wösten, J.H.M. and Bouma, J. 1993. Sampling strategies for measurement of soil hydraulic properties to predict rice yield using simulation models. Geoderma, 59: 1-20.

WRB, 1998. A world reference base for soil resources. In: O.C.S. J.A. Deckers, F.O. Nactergaele, L.R. Oldeman, R. Brinkman (Editor), World Soil Resources, Report nº 84 . FAO-ISRIC-AISS, Rome, Italia.

Zinn, B. and Harvey, C.F. 2003. When good statistical models of aquifer heterogeneity go bad: A comparaison of flow, dispersion, and mass transfer in connected and multivariate hydraulic conductivity fields. Water Resources Research, 39(3): 1-18. 


\section{$481 \quad$ List of figures}

482 Figure 1: Binary 3D representation of the E\&BT horizon, with ochre (orange color on the figure) and 483 pale elementary pedological volumes (light grey color on the figure) obtained after electrical 484 resistivity tomography (from Frison 2008).

Figure 2: Water retention curve of the horizon studied.

-a- Water retention curve determined by the evaporation method on 8 pale EPVs and 9 ochre EPVs. The bold lines represent the mean curve for each type of EPV. At some water potentials, a Student ttest has enabled determining if the volumetric water content was significantly different (the letters are different when the water contents are significantly different).

-b- Effective water retention curve at horizon scale for case 1 (black line). (The ochre and grey lines represent the highest contrast in water retention curves at EPV scale).

Figure 3: Unsaturated hydraulic conductivity curve at EPV scale.

-a- Unsaturated hydraulic conductivity curve determined by the evaporation method on 8 pale EPVs and 9 ochre EPVs. The bold lines represent the mean curve for each type of EPV. At some water potentials, a Student t-test has enabled determining if the volumetric water content was significantly different (the letters are different when the water contents are significantly different).

-b- Ratio between the hydraulic conductivity curve of the pale and ochre EPVs for the three study cases (case 1: square symbols; case 2: circle symbols; case 3: cross symbols).

Figure 5: Decision tree for effective hydraulic conductivity determination in an anisotropic medium assuming vertical fluxes. 
List of tables

Table 1: Particle-size distribution of the pale and ochre EPVs in the upper and lower parts of the E\&BT horizon. (The particle-size distribution was determined according to the French normalized protocol X 31-107).

Table 2: Bulk density at sampling and saturated water content of the pale and ochre EPVs in the upper and lower parts of the E\&BT horizon

Table 3: Hydraulic conductivity parameters for the pale and the ochre EPVs and for the three cases studies.

Table 4: Calculated surface area: $\mathrm{S}_{\mathrm{EPV}}$ between pale and ochre EPV hydraulic conductivity, $\mathrm{S}_{\mathrm{Wiener}}$ between Wiener bounds, $\mathrm{S}_{\text {Cardwell-Parsons }}$ between, respectively, Cardwell and Parsons bounds, $\mathrm{S}_{\text {Cardwell- }}$ Parsons_Numerical Simulation, $S_{\text {Wiener_Numerical Simulation }}$ between Cardwell and Parsons upper bound, lower bound, Wiener upper bound, lower bound and effective hydraulic properties defined with the numerical simulation. 


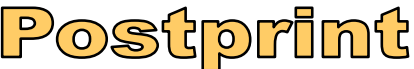

Version définitive du manuscrit publié dans / Final version of the manuscript published in :

Vadose Zone Journal, 2011, 10(1), 450-458, ～http://dx.doi.org/10.2136/vzj2010.0008

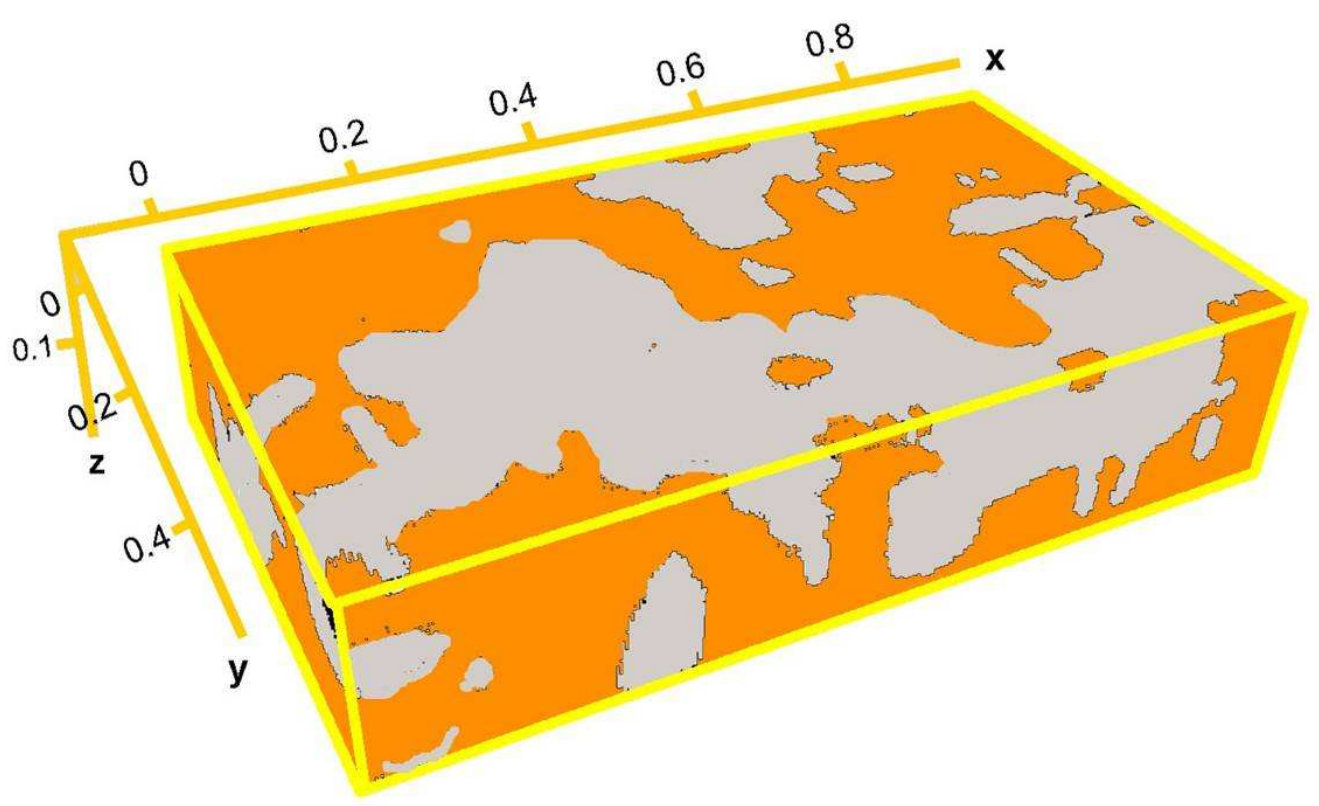

Figure 1 


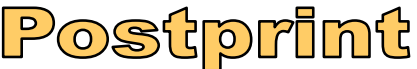

Version définitive du manuscrit publié dans / Final version of the manuscript published in :

Vadose Zone Journal, 2011, 10(1), 450-458, ․ㅐtp://dx.doi.org/10.2136/vzj2010.0008

a

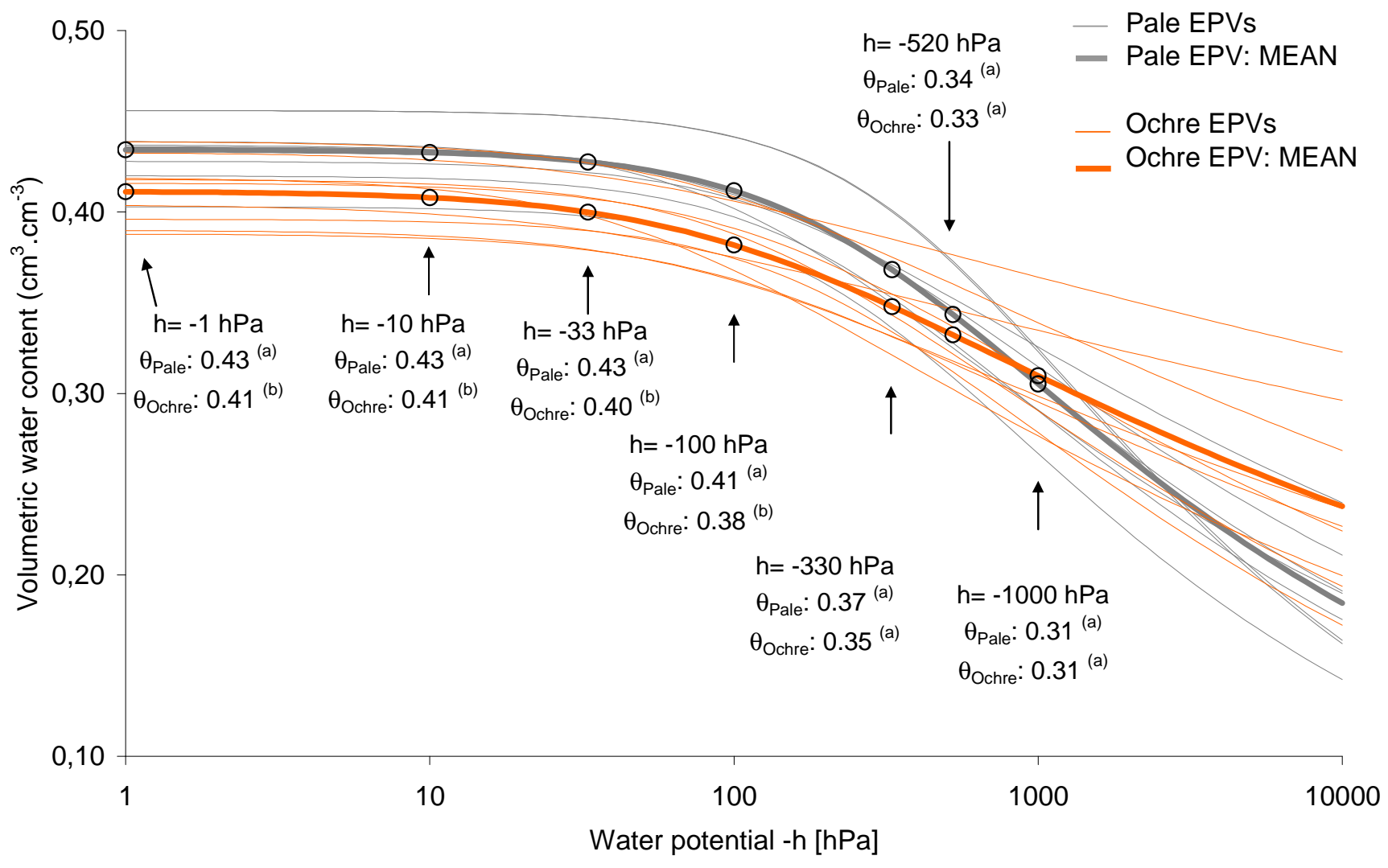

b

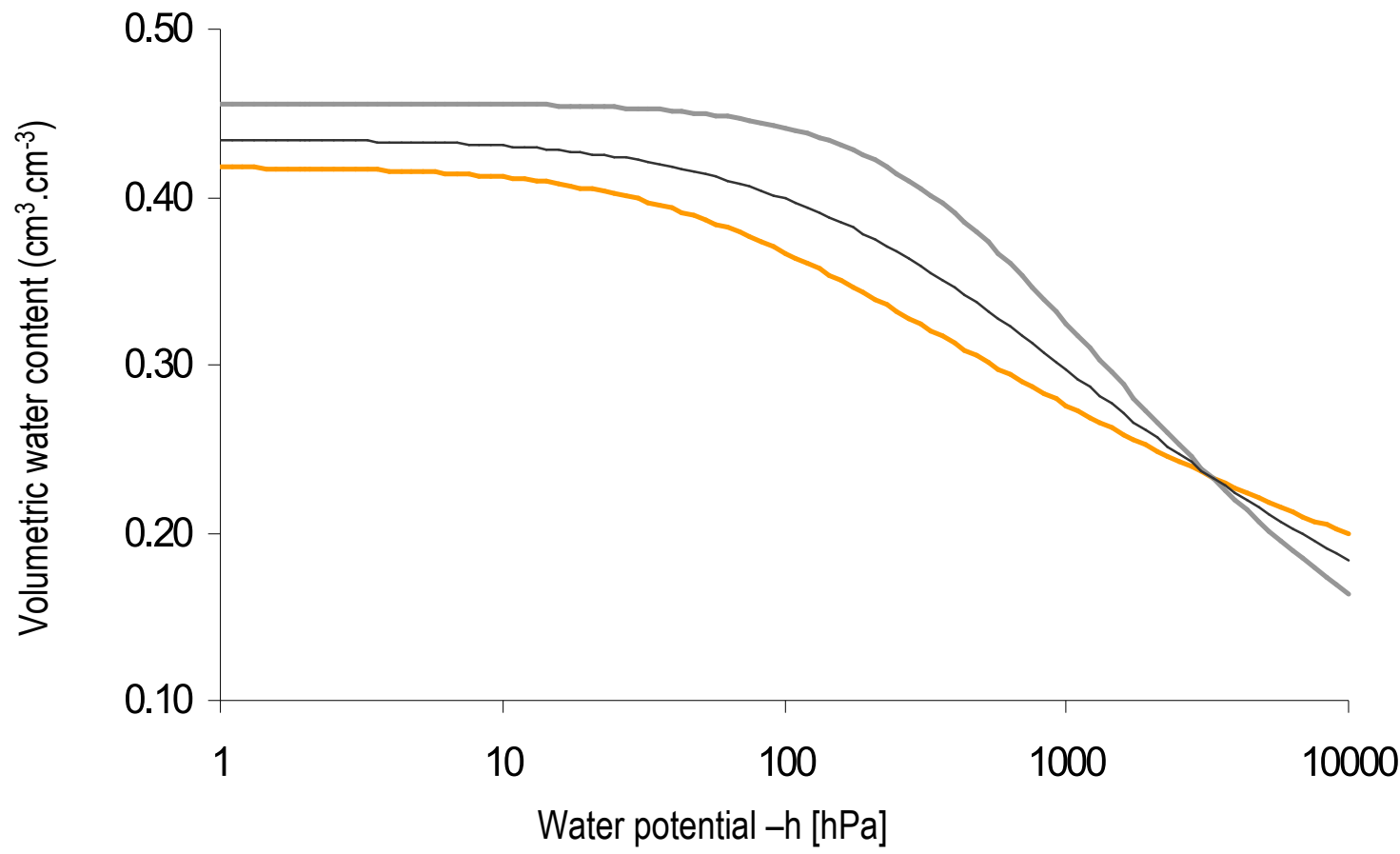

Figure 2 


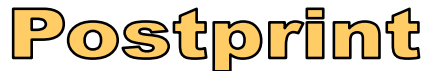

Version définitive du manuscrit publié dans / Final version of the manuscript published in :

Vadose Zone Journal, 2011, 10(1), 450-458, ․ㅐtp://dx.doi.org/10.2136/vzj2010.0008

a

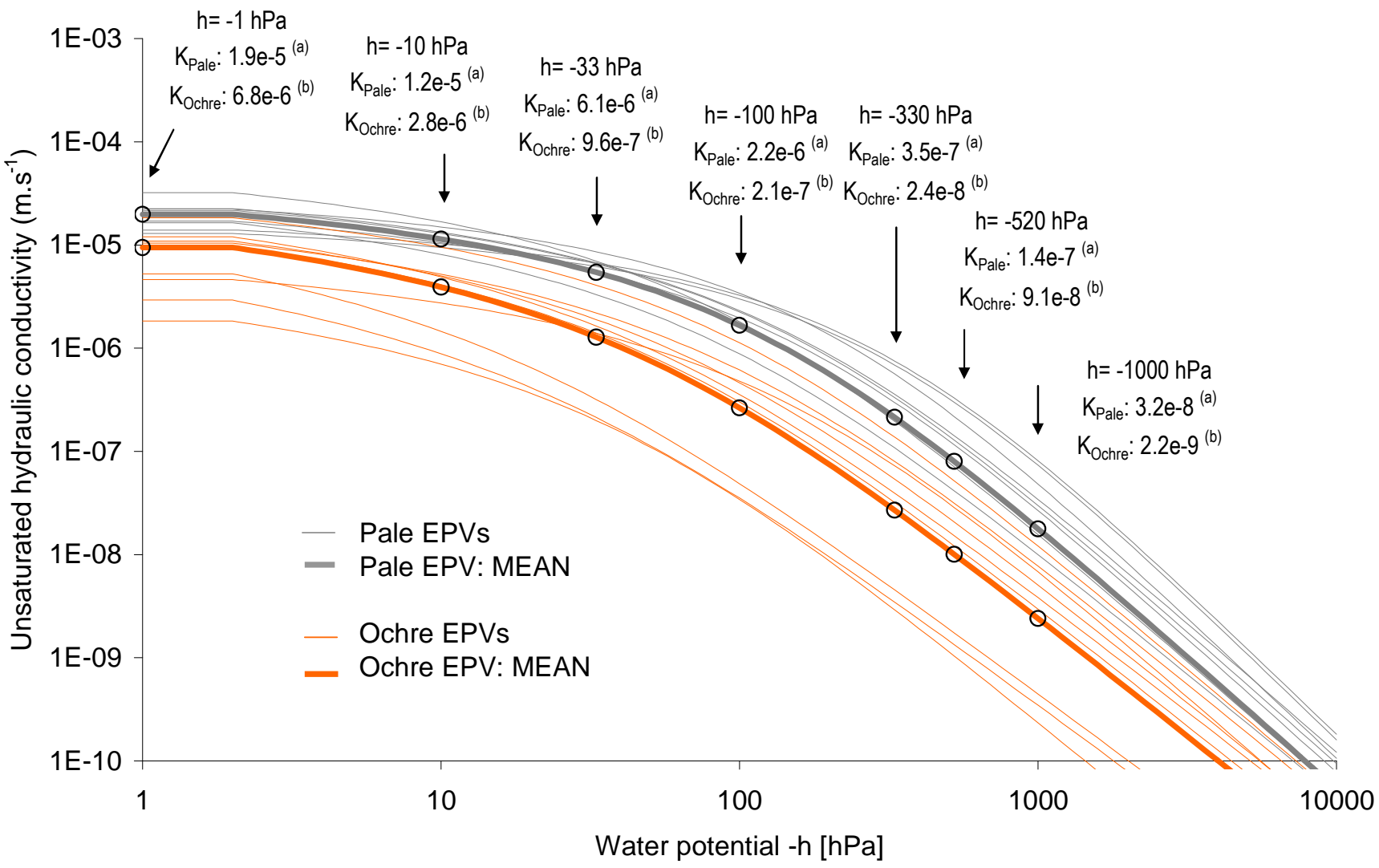

b

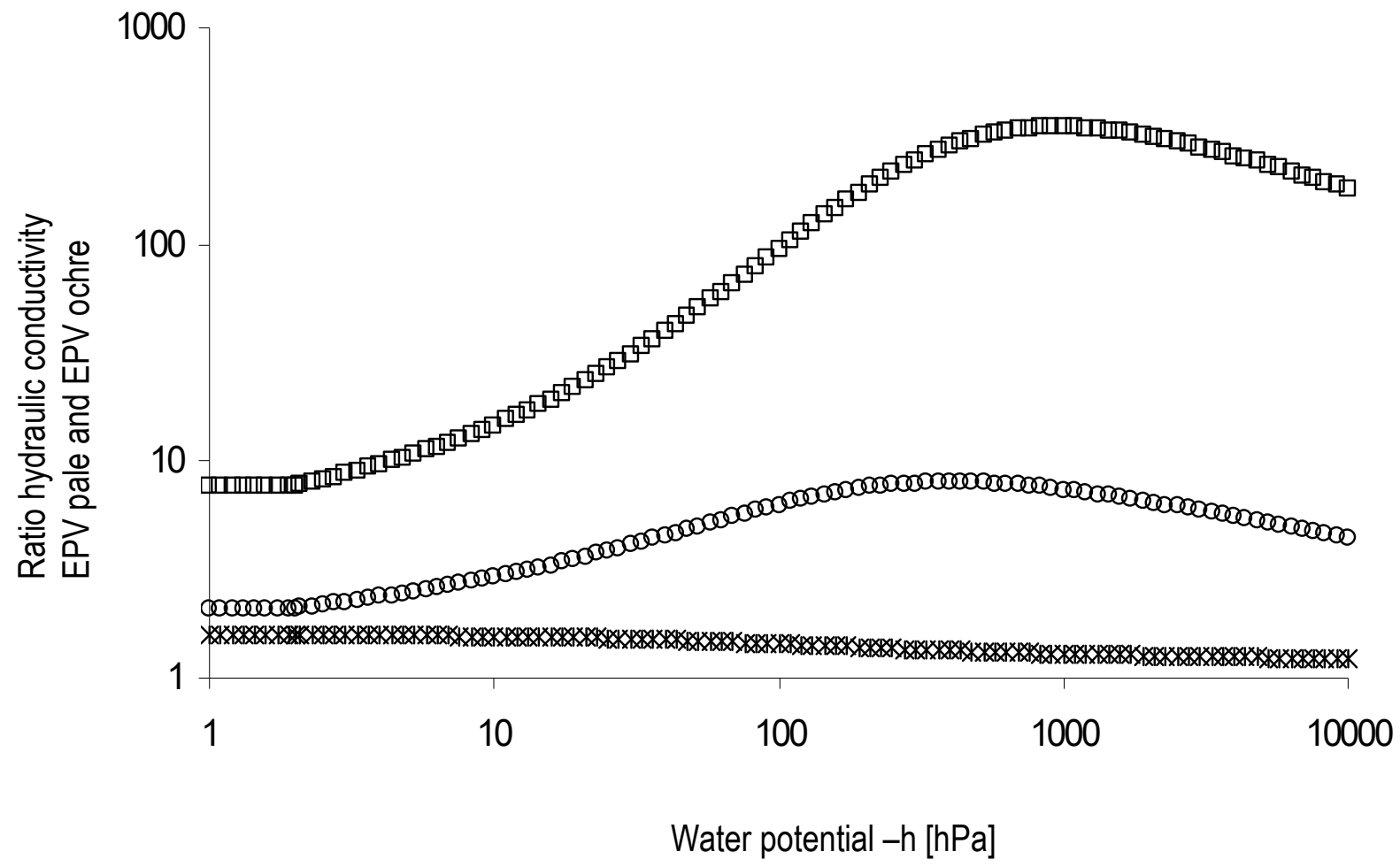

Figure 3 


\section{POS\{}

Version définitił/e du manuscrit publié dans / Final version of the manuscript published in : Vadose Zone Journal, 2011, 10(1), 450-458, ～http://dx.doi.org/10.2136/vzj2010.0008
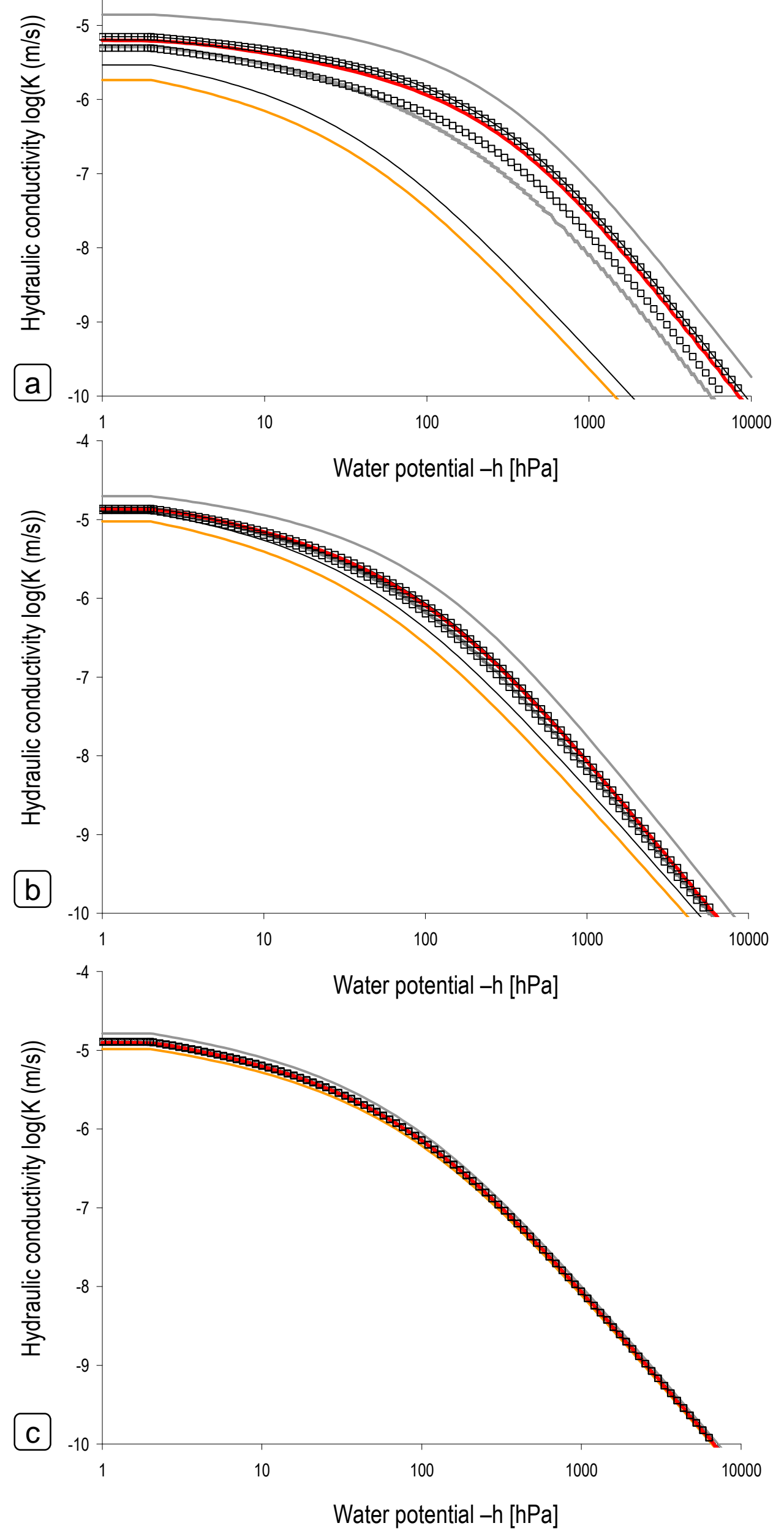

Figure 4 


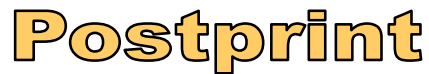

Version définitive du manuscrit publié dans / Final version of the manuscript published in :

Vadose Zone Journal, 2011, 10(1), 450-458, ～http://dx.doi.org/10.2136/vzj2010.0008
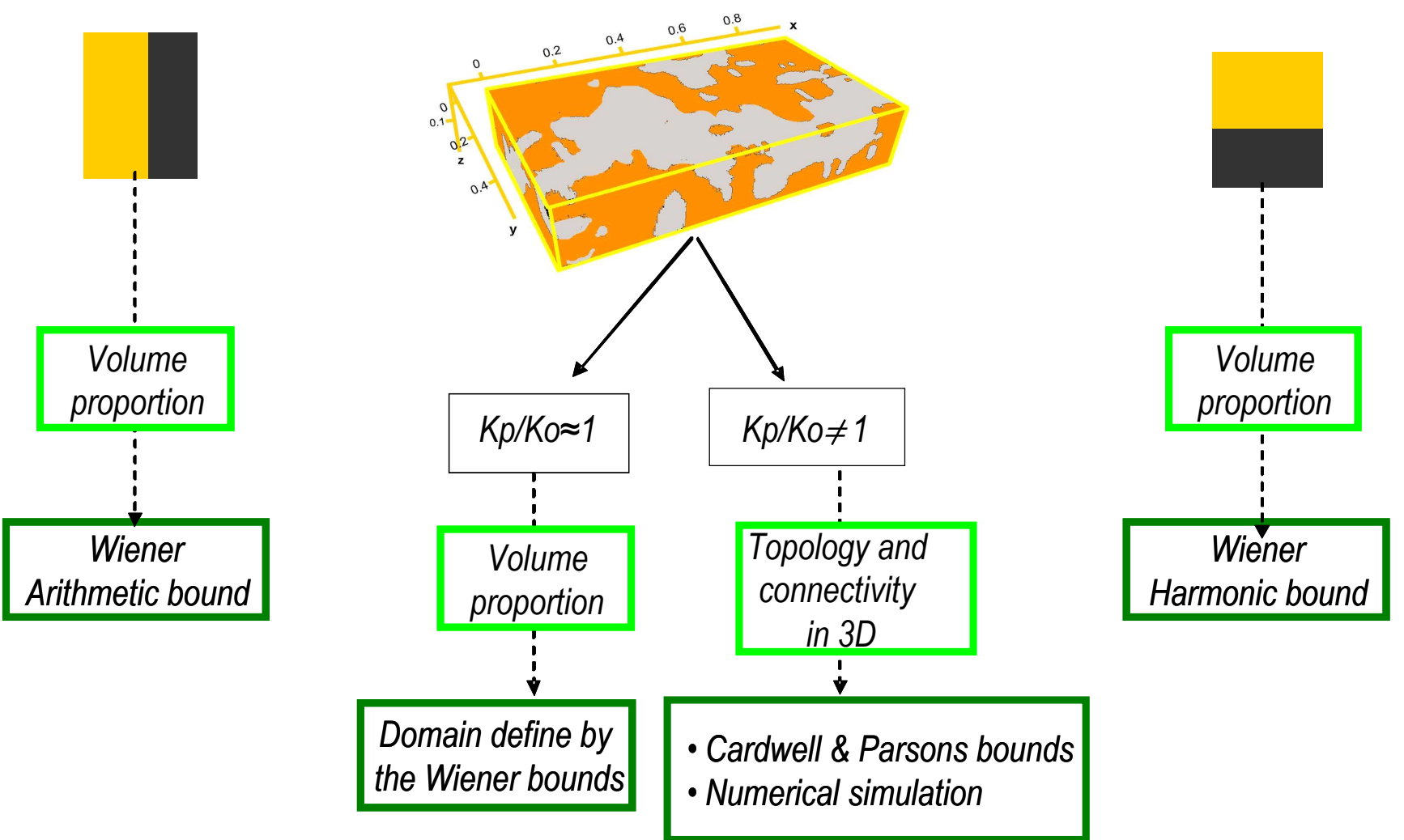

Figure 5 


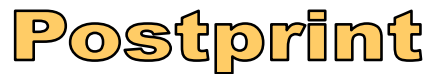

Version définitive du manuscrit publié dans / Final version of the manuscript published in :

Vadose Zone Journal, 2011, 10(1), 450-458, ～http://dx.doi.org/10.2136/vzj2010.0008

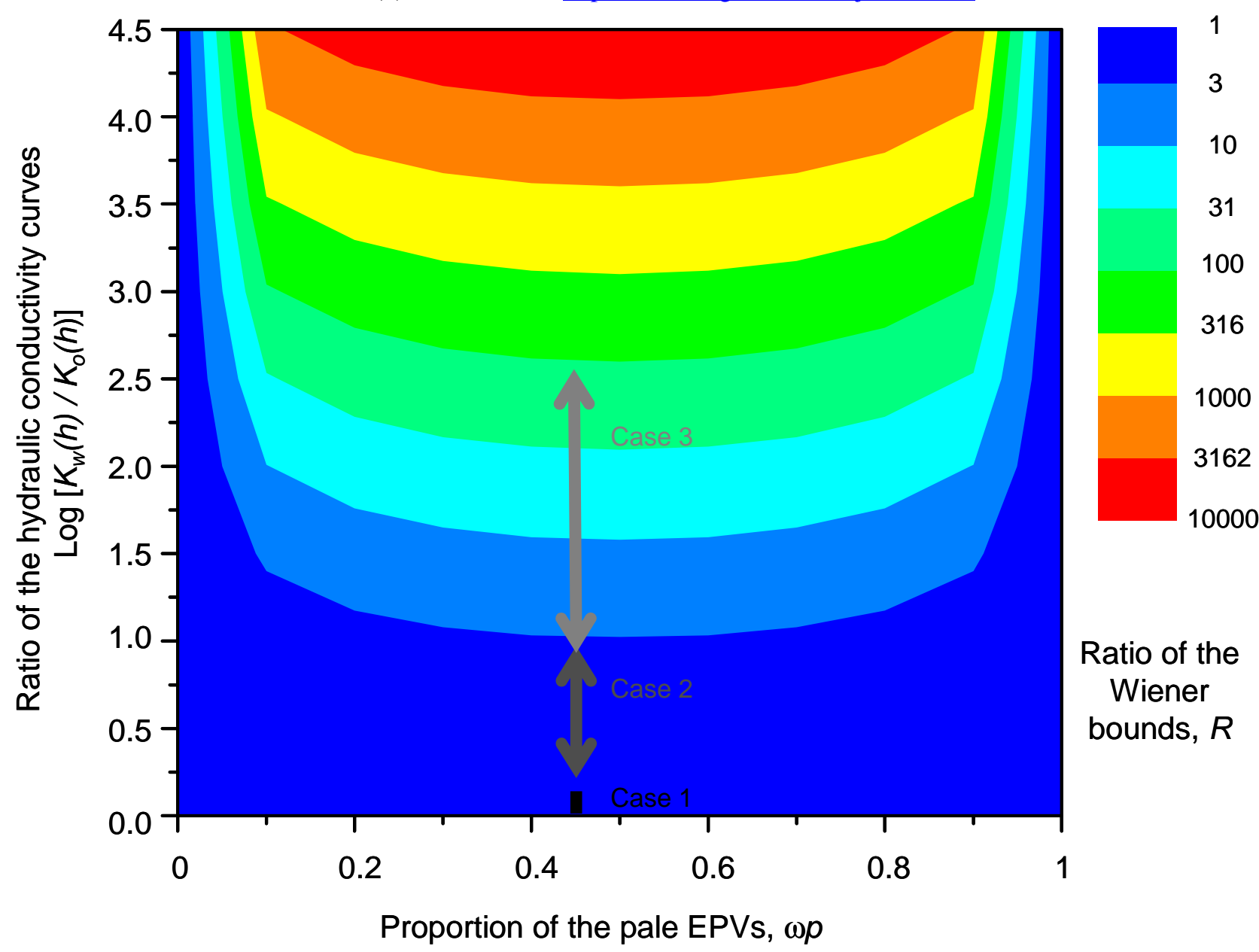

Figure 6 


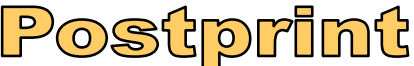

Version définitive du manuscrit publié dans / Final version of the manuscript published in :

Vadose Zone Journal, 2011, 10(1), 450-458， http://dx.doi.org/10.2136/vzj2010.0008

\begin{tabular}{l|l|l|l}
\hline \multirow{2}{*}{ Depth $(\mathrm{m})$} & \multicolumn{3}{|l}{ Particle-size distribution $\left(\mathrm{g} \mathrm{kg}^{-1}\right)$} \\
\cline { 2 - 4 } & $<2 \mu \mathrm{m}$ & $2-50 \mu \mathrm{m}$ & $50-2000 \mu \mathrm{m}$ \\
\hline $0.35-0.45$ & $182^{\mathrm{p} / 248^{\circ}}$ & $714^{\mathrm{p}} / 659^{\circ}$ & $104^{\mathrm{p}} / 93^{\circ}$ \\
\hline $0.45-0.55$ & $213^{\mathrm{p}} / 322^{\circ}$ & $706^{\mathrm{p}} / 620^{\circ}$ & $81^{\mathrm{p}} / 58^{\circ}$ \\
\hline
\end{tabular}

.p: pale EPV

o: ochre EPV

Table 1

\begin{tabular}{llllll}
\hline & $\mathrm{Nb}(-)$ & $\begin{array}{l}\text { Mean bulk } \\
\text { density }\left(\mathrm{g} \mathrm{cm}^{3}\right)\end{array}$ & $\begin{array}{l}\text { Mean saturated water } \\
\text { content }\left(\mathrm{cm}^{3} \mathrm{~cm}^{-3}\right)\end{array}$ & $\begin{array}{l}\text { Coefficient of } \\
\text { variation }(\%)\end{array}$ \\
\hline Pale EPV & 15 & 1.53 & 0.423 & 2.76 \\
Ochre EPV & 18 & 1.57 & 0.408 & 3.75 \\
\hline
\end{tabular}

Table 2

\begin{tabular}{l|cc|cc|cc}
\hline & \multicolumn{2}{|c|}{ case 1 } & \multicolumn{2}{c|}{ case 2 } & \multicolumn{2}{c}{ case 3 } \\
& pale & ochre & pale & ochre & pale & ochre \\
\hline$\theta_{s} / \mathrm{cm}^{3} \mathrm{~cm}^{-3}$ & 0,46 & 0,42 & 0,43 & 0,41 & 0,44 & 0,42 \\
$\theta_{r} / \mathrm{cm}^{3} \mathrm{~cm}^{-3}$ & 0,001 & 0,016 & 0,033 & 0,021 & 0,034 & 0,005 \\
$\alpha / \mathrm{m}^{-1}$ & 0,23 & 1,64 & 0,55 & 1,21 & 0,72 & 0,66 \\
$n$ & 1,33 & 1,15 & 1,23 & 1,13 & 1,16 & 1,15 \\
$K_{s}\left(\mathrm{~ms}^{-1}\right)$ & $1,40 \mathrm{E}-05$ & $1,83 \mathrm{E}-06$ & $1,98 \mathrm{E}-05$ & $9,46 \mathrm{E}-06$ & $1,64 \mathrm{E}-05$ & $1,04 \mathrm{E}-05$ \\
\hline
\end{tabular}

Table 3

\begin{tabular}{l|r|r|r|r|r|r|r|} 
& \multicolumn{1}{|c|}{ SEPV } & \multicolumn{1}{c|}{ Swiener } & Scardwell-Pearson & \multicolumn{2}{|c|}{ Scardwell-Pearson_Numerical simulation } & \multicolumn{2}{|c|}{ Swiener_Numerical simulation } \\
& 184,54 & 125,67 & 29,40 & 7,58 & 21,82 & 8,29 & 117,38 \\
case 1 & 66,63 & 24,15 & 9,86 & 1,59 & 8,27 & 1,98 & 22,17 \\
case 2 & 15,47 & 1,40 & 0,61 & 1,02 & 0,42 & 1,09 & 0,58 \\
\hline
\end{tabular}

